\title{
Macromolecular Systems for Vaccine Delivery
}

\author{
G. MUŽÍKOVÁ ${ }^{1}$, R. LAGA ${ }^{1}$ \\ ${ }^{1}$ Institute of Macromolecular Chemistry of the Czech Academy of Sciences, Prague, Czech \\ Republic
}

Received July 14, 2016

Accepted July 14, 2016

\begin{abstract}
Summary
Vaccines have helped considerably in eliminating some lifethreatening infectious diseases in past two hundred years. Recently, human medicine has focused on vaccination against some of the world's most common infectious diseases (AIDS, malaria, tuberculosis, etc.), and vaccination is also gaining popularity in the treatment of cancer or autoimmune diseases. The major limitation of current vaccines lies in their poor ability to generate a sufficient level of protective antibodies and $\mathrm{T}$ cell responses against diseases such as HIV, malaria, tuberculosis and cancers. Among the promising vaccination systems that could improve the potency of weakly immunogenic vaccines belong macromolecular carriers (water soluble polymers, polymer particels, micelles, gels etc.) conjugated with antigens and immunistumulatory molecules. The size, architecture, and the composition of the high molecular-weight carrier can significantly improve the vaccine efficiency. This review includes the most recently developed (bio)polymer-based vaccines reported in the literature.
\end{abstract}

\section{Key words}

Vaccine delivery - Cellular and humoral immunity - Polymer immunostimulants • Adjuvants

\section{Corresponding author}

G Mužíková, Institute of Macromolecular Chemistry of the Czech Academy of Sciences, Heyrovského nám. 2, 16206 Prague 6, Czech Republic. Fax: $\quad+420296809410$. E-mail: muzikova@imc.cas.cz

\section{Introduction}

The development of vaccination dates as far back as to $1,000 \mathrm{AD}$ when the Chinese protected themselves from smallpox. They observed that a person who had survived smallpox was immune for his or her whole life (Silvers et al. 2001). They transplanted pus or scabs from the infected person into a skin wound or the nostrils of a healthy person. Indians also protected themselves from snake poisoning by ingesting small amounts of the snake venom in advance. Vaccination has progressed much further now. At present, not only are there vaccines against infectious diseases elicited by pathogenic microorganisms but also there are new types of vaccines available, including allergy vaccines and cancer vaccines. The major component of all vaccines is an antigen, a molecule capable of inducing an immune response. In general, an antigen can be derived from any harmful substance recognizable by $\mathrm{T}$ cell and $\mathrm{B}$ cell receptors, leading to an antigen-specific $\mathrm{T}$ cell and antibody response. The examples of antigens are various peptides, polysaccharides or lipids that bind to antigenspecific receptors of immune cells. These molecules can be either (part of) an exogenous pathogenic microorganism (e.g. virus, bacterium, or yeast) or part of the host itself (e.g. molecules resulting from inflammation or from cancer cells). Current vaccines are comprised of two major types, whole organism vaccines and subunit vaccines. The whole viruses or bacteria are usually attenuated or inactivated but manufacturing cost, antigenic competition, and potential safety concerns have limited their use. For the safety reason, subunit vaccines containing only the immunogenic parts of microorganisms, or possibly fragments of their DNA that are not able to replicate in host, are mostly used. Other than an antigen, vaccines commonly also includes an 
adjuvant and additional substances, such as preservatives (e.g. formaldehyde or thimerosal), antibiotics to prevent germ growth during the vaccine production or in the final product, or stabilizers (e.g. $\mathrm{MgSO}_{4}$ and lactose-sorbitol) for live attenuated vaccines (http://www.cdc.gov/ vaccines/pubs/pinkbook/index.html). The adjuvant is an auxiliary component added to a vaccine that enhances or modifies the adaptive immune response to an antigen. This description fits both immunostimulatory molecules (e.g. pathogen-associated molecular patterns (PAMPs)) and delivery systems (e.g. polymer carriers of immunostimulants or antigens) (Brito et al. 2014).

Despite the considerable progress that has been made in the development of vaccines in the past decades, there is still ample scope for the preparation of safer and, above all, more efficient vaccines. The most pronounced limiting factors of some currently used vaccines, making impossible to use them for prophylaxis of some serious population diseases such as HIV, malaria or cancers, are their insufficient ability to generate protective antibody and $\mathrm{T}$ cell responses, adverse events (fever, vomiting, febrile seizures, etc.) caused by hypersensitivity of an organism to some of the key components in the vaccine (Movahedi et al. 2015), or the necessity of multiple doses (Baxendale et al. 2011) caused by the relatively low and short-term effects of some vaccines. Taken together, these observations reveal a clear need for the development of delivery systems that are able to reliably overcome these obstacles. One of the most promising approaches appears to be the use of a macromolecular carrier as a platform for the delivery of an antigen and an adjuvant. The key role of the macromolecular delivery systems is to improve the potency of weakly immunogenic subunit vaccines, prolong the antigen presentation and last but not least to reduce the toxicity of small-molecular-weight immunostimulants which could be also co-delivered on the same carrier together with an antigen. There are many distinct polymer-based vaccines described in the literature varying in macromolecular carrier composition (e.g. polymers based on poly(L-lactic acid) (Baxendale et al. 2011), poly(acrylate)s (Liu et al. 2015b), or chitosan (Prego et al. 2010)) and architecture (e.g. polymer micelles (Brubaker et al. 2016), polymer particles (Rajapaksa et al. 2010), or dendrimers (Sheng et al. 2008)), as well as in the method of incorporation of an antigen and an adjuvant with the polymer carrier (e.g. covalent attachment (Lynn et al. 2015) or encapsulation (Singh et al. 2015)). Figure 1 schematically represents types of currently used vaccines.
This review focuses on recent trends and novelties in polymer-based and natural macromoleculebased vaccines. We searched for interesting examples in the literature that have been published since 2010 .

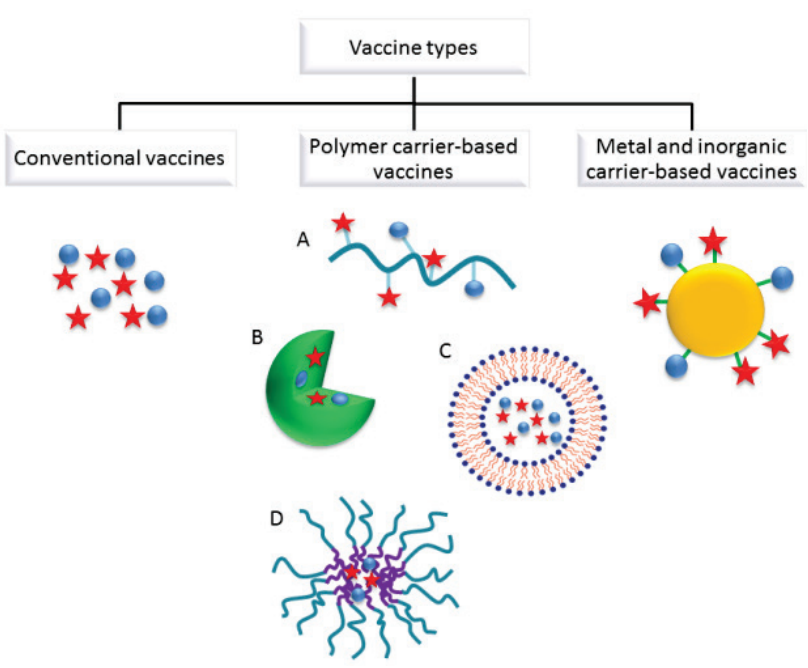

Fig. 1. Schematic representation of vaccine types. (A) linear hydrophilic polymer carrier, (B) (nano)particle, (C) liposome, (D) polymer micelle.

\section{Vaccination}

The key principle of the vaccine is the induction of a specific adaptive antibody and $\mathrm{T}$ cell immune response towards the inserted antigen (Fig. 2) and, thus, the activation of immunologic memory in case that the antigen is encountered in the future to eliminate the risk of an infection or a disease (Zepp 2010).

The father of vaccination, Dr. Edward Jenner, discovered the protective effect of cowpox against smallpox in 1789. He was followed by Louis Pasteur, who performed many experiments on animals and successfully vaccinated people against rabies, which was often a cause of death after a bite from a wild animal, and anthrax (Silvers et al. 2001). Since then, vaccination has prevented many deaths every year and, some diseases have been (almost) eradicated because of vaccination (e.g. smallpox, diphtheria, polio, and rubella) (Roush et al. 2007).

The first vaccines contained only live microorganisms isolated from infected animals. Although this type of vaccine appeared to be very potent from the vantage point of that time, safety concerns have led to the gradual abandonment of their production. Later generations of vaccines contained live attenuated microorganisms that were mutated in the laboratory so 


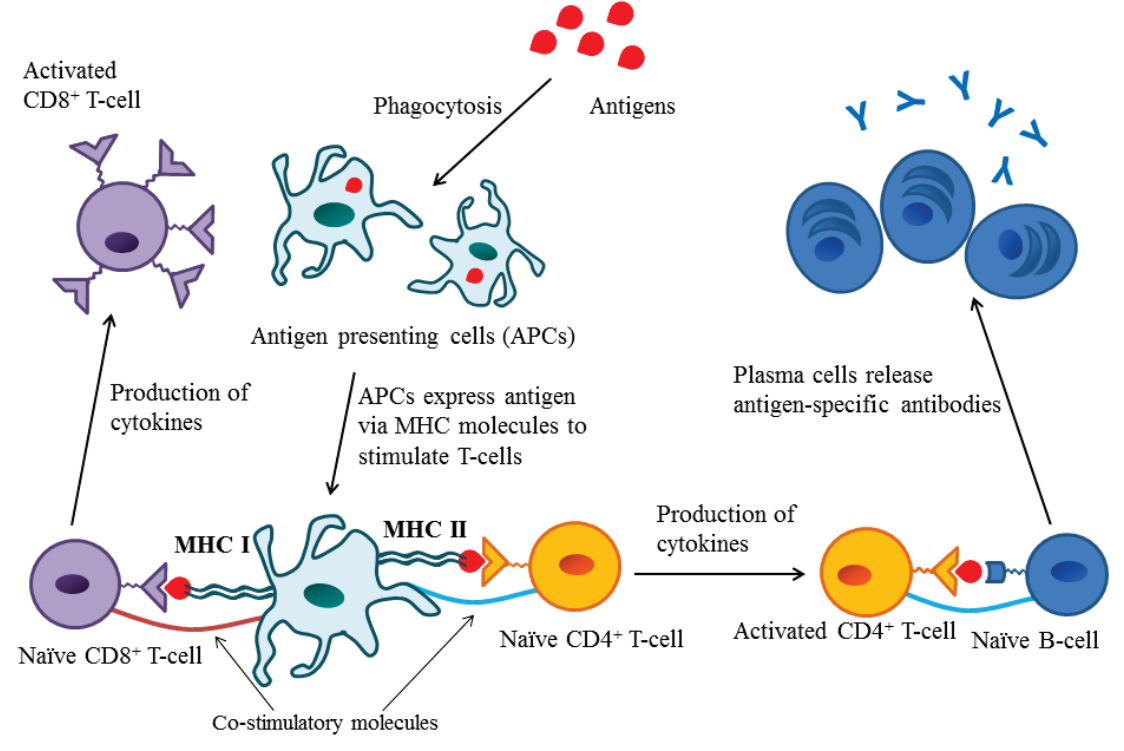

Fig. 2. Basic scheme of adaptive immunity induction. An antigen is taken up and processed by dendritic cell (antigen presenting cell) followed by presentation of antigen fragments on the cellular surface to T-cells via MHC II or MHC I molecules. Naïve CD4+ T-cell recognizes $\mathrm{MHC}$ II/anti-gen protein complex, maturates and binds to B-cell creating plasma cell that releases epitope-specific antibodies. Naïve CD8+ T-cells are activated by binding to the MHC I/antigen protein complex presented on the APCs and maturate to become activated cytotoxic T-cells specifically recognizing the antigen epitopes. Both mechanisms are important for formation of adaptive immunity. that they lost their virulent properties. The troublesome disadvantage of live attenuated vaccines is that the microorganisms can mutate or transform to a virulent form and cause illness or adverse effects. On the other hand, live attenuated vaccines elicit strong cellular and antibody responses, so that one or two doses of the vaccine are sufficient for lifelong protection. Examples of live attenuated vaccines available on the market are the vaccines against yellow fever, measles, and rubella.

To prevent the adverse effects caused by live pathogens, killed vaccines have been prepared. Killed vaccines contain microorganisms inactivated by antibiotics, heat, chemicals, or radiation. They are safer and more stable than live attenuated vaccines. Killed vaccines approved by FDA include ones against hepatitis A, poliovirus, and rabies (http://www.fda.gov/ BiologicsBloodVaccines/Vaccines/ApprovedProducts/uc m093830.htm).

Some infectious diseases are not directly caused by bacteria but rather by their toxins, which are isolated from the microorganisms and are used as part of some vaccines (e.g. diphtheria vaccine or tetanus toxoid vaccine).

Another type of vaccine, the so called subunit vaccines, contains only fragments of a pathogen, such as surface proteins, glycoproteins or short peptide sequences that are responsible for eliciting of immune response. Because subunit vaccines do not contain other parts of a pathogen, the occurrence of adverse effects to the vaccine is significantly lower that for live attenuated vaccines. Subunit vaccines might contain up to 20 or more different antigens from a single bacterium because in the case of some microorganisms, it is challenging to identify the epitopes that most stimulates the production of antibodies and $\mathrm{T}$ cell responses. Examples include the subunit vaccine Recombivax HB against hepatitis $B$ virus (https://www.merckvaccines.com/Products/Recombivax $\mathrm{HB} /$ Pages/home) or the human papilloma virus.

The next generation of subunit vaccines is the DNA or RNA vaccine (Kutzler et al. 2008). Such vaccines uses the recombinant technology to insert the specific DNA or RNA sequence (Kallen et al. 2013), encoding antigen protein derived from certain structural motifs of microbes, to the DNA vector. Once the vector is delivered and transfected into the nucleus of immune cells, the cells start producing the specific amino acid sequence (antigen) that is subsequently displayed on their surface where it forms specific complex structures with the MHC proteins. Such antigen-decorated cells are then recognized by the antigen-specific components of adaptive immune system. The advantage of DNA vaccines is mainly their inability to cause infection, their relatively high reproducibility, and their long-term stability. The DNA sequence of the plasmid can be easily modulated and combined with various adjuvants (alum, polysaccharide, liposomes) or polymer carriers, e.g. poly(lactic-co-glycolic acid) (Saade et al. 2012), or viral based vectors (Anderson et al. 2007). On the other hand, the use of the DNA vaccines is limited by their low immunogenicity, which is due to the relatively low transfection efficiency of the plasmid, and the use of only protein antigens. The big challenge for improving the immunogenicity of such vaccines is to find new delivery system that will achieve reliable and safe transport of the plasmid to the target cells, cause effective penetration of the plasmid through the cell membrane and ensure the 
release of the plasmid in cell cytoplasm. Adenoviral and retroviral vectors, synthetic polycations or cationic liposomes are among the most studied delivery systems that have great promise for the future (Maubant et al. 2011). The FDA has not approved any DNA vaccines so far, but a DNA vaccine against the Japanese encephalitis virus is in the third phase of clinical trials (Appaiahgari et al. 2010).

Currently, the FDA has approved approximately 50 vaccines for various applications (http://www.fda.gov/BiologicsBloodVaccines/Vaccines/ ApprovedProducts/ucm093830.htm). Apart from the vaccines against infectious diseases that prevent the patient from infection upon a repeat encounter with a pathogen (prophylactic vaccines), therapeutic vaccines are also being developed. Therapeutic vaccines help to treat ongoing cancer or allergy by supporting the immune system and are tailor-made for each patient. Therapeutic cancer vaccines contain autologous whole cancer cells or antigens derived from the cancer cells. The FDA has approved the vaccine PROVENGE $®$ for treatment of asymptomatic or minimally symptomatic metastatic castration resistant prostate cancer (http://www.fda.gov/biologicsbloodvaccines/cellulargene therapyproducts/approvedproducts/ucm210215.htm); this vaccine is based on the autologous mononuclear cells (including APCs) activated by the prostatic acid phosphatase (PAP) antigen that is expressed in prostate cancer cells. PAP was linked to an adjuvant, granulocytemacrophage colony-stimulating factor (GM-CSF), creating the recombinant protein PAP-GM-CSF and was incubated with a patient's APCs, which processed the antigen and expressed the antigen fragments on the surface. Whole cancer cells express different antigens, which naturally occur in the body, so the immune system is partially tolerant towards them, and the immunogenicity of such vaccines can be poor; there is additionally a risk of developing autoimmunity. Another approach is based on the use of a single antigen from cancer cells. There are many known antigens present on cancer cells, for example, CD19 and BCR-ABL on acute lymphocytic leukemia cells or CD30 on Hodgkin's lymphoma cells (Wurz et al. 2016). This approach includes various vaccines, for example, anti-idiotype vaccines, anti-carbohydrate-antigen vaccines, or different peptide-based vaccines (Mittendorf et al. 2008).

Currently available allergy vaccines are used for the treatment of common allergies, such as hay fever, asthma, house dust mite allergy, or insect sting allergy.
The vaccination involves gradually increasing doses of purified allergens, which should desensitize the patient (http://www.alkabello.com/products/Pages/SectionFront. aspx). Allergen immunotherapy is long-lasting process (up to five years) because many doses are needed. The vaccine is generally administered subcutaneously; however, research now focuses on preparation of oral vaccines (Ai et al. 2015) or allergen carriers (alginate/chitosan microparticles (Suksamran et al. 2011) or hydroxypropyl methyl cellulose (Wood et al. 2015), which prolong the effect of the allergen in the body so that the number of doses can be reduced. The efficacy of the vaccines (and the duration of the immunization) can also be improved by chemically altering the allergen, usually by sparse crosslinking of the proteins in the allergen extracts using bifunctional crosslinkers, such as glutaraldehyde or formaldehyde, creating an ,allergoid“ that contains the linear epitopes recognized by APC surface receptors but has less reaginic (allergy causing) epitopes or by the addition of adjuvants, such as Toll-like receptor agonists (Casale et al. 2014).

Although modern subunit vaccines represent safe and relatively efficient immunological tools in the prophylaxis and treatment of numerous infectious diseases, there is still ample scope for the improvement of vaccine immunogenicity and durability. For that reason, auxiliary immunostimulatory compounds, so-called adjuvants, are currently commonly used as an integral part of a vaccine.

\section{Adjuvants}

Adjuvants in vaccines are needed mainly because they enhance the immune response directed against the antigen. Moreover, adjuvants may stabilize the antigens (Zhu et al. 2013) or prolong the circulation of the antigen in the blood (Saini et al. 2013). There are several mechanisms through which the adjuvants activate the immune system: (1) they interact with the pathogenrecognition receptors on APCs and thus cause the release of inflammatory cytokines at the injection site, which recruit various immune cells; (2) they stimulate the maturation of APCs and their migration to lymph nodes; (3) macromolecular and hydrophobic adjuvants create a "depot" in the injection site and thus prolong antigen presentation; (4) some adjuvants may cause tissue destruction - the danger signals of stressed or infective cells activate the APCs; and (5) adjuvants increase the antigen uptake (Awate et al. 2013, Schijns 2000). The 
first generation of adjuvants comprises aluminum salts as well as emulsions, liposomes, and micro- or nanoparticles, which can simultaneously serve as antigen delivery systems. The second generation of adjuvants combines the mentioned antigen delivery systems with immune potentiators (Toll-like receptor agonists) (Brito et al. 2014).

The adjuvants currently approved by U.S. Food and Drug Administration (FDA) are aluminum salts, such as aluminum hydroxide, aluminum phosphate, and alum (potassium aluminum sulfate), which are used, for example, in the pneumococcal conjugate vaccine and the hepatitis B vaccine. AS03 adjuvant, consisting mainly of D,L-alpha-tocopherol (vitamin E) and squalene (oil-inwater emulsion) is also FDA-approved for the prevention of $\mathrm{H} 5 \mathrm{~N} 1$ influenza, as is AS04, a combination of aluminum hydroxide and monophosphoryl lipid $\mathrm{A}$, as part of a cervical cancer vaccine (Cervarix) (http://www.fda.gov/BiologicsBloodVaccines/SafetyAvai lability/VaccineSafety/ucm187810.htm). In Europe, the squalene-based adjuvant MF59 (Podda et al. 2003), developed by Novartis, is aslo approved. When designing a new vaccine, it is important to find a mutually compatible combination of an antigen and an adjuvant that invokes the optimal immune response (Pasquale et al. 2015). Other than these adjuvants, many others exist in the literature that have not yet been approved but that have great potential to become an important component of commercially available vaccines in the near feature. These are, for example, bacteria-derived adjuvants, including lipids and lipopolysaccharides (Shanmugam et al. 2012), cytokines that are used in DNA vaccines for animals (Turell et al. 2003, Yen et al. 2007), natural substances, such as saponin, or statistical copolymers of lactide and glycolide (Jaganathan et al. 2006, Saini et al. 2013), whose advantage is that they can be simultaneously used as particle-based antigen carriers serving as a depot. Interesting adjuvants from the perspective of macromolecular vaccines are Toll-like receptor (TLR) agonists. Toll-like receptors are localized on the membranes or endosomal compartments of dendritic cells, macrophages, and natural killer cells and comprise about thirteen structurally different classes. Individual TLRs recognize various structural motifs present on pathogens (or their low-molecular-weight analogues), such as lipopeptides, hyaluronic acid fragments, single-stranded RNA, and imidazoquinoline. Some of the molecules that bind to the TLR (so called TLR agonists or TLR ligands) can be chemically modified and covalently attached to the antigen or to the polymer carrier without losing their immunostimulatory abilities. This is documented, for example, for a TLR-2 agonist linked to a chitosan-based nanocarrier (Heuking et al. 2009), a TLR-7 agonist attached to poly(HPMA) (Lynn et al. 2015), and a TLR-4 agonist linked to a polyethylenimine-based carrier (Li et al. 2016). One of the TLR agonists, specifically the TLR-7/8a, Imiquimod, is FDA-approved for the treatment of several skin diseases, such as genital warts and actinic keratoses (http://www.fda.gov/Safety/MedWatch/SafetyInformatio n/ucm232204.htm).

However, some effective adjuvants that show satisfactory results in animals are not convenient for use in humans because of their relatively high toxicity (e.g. Freund's complete adjuvant). Ligi et al. (2015) claim that aluminum salts accumulate in monocyte cells and can cause autoimmune diseases. They showed that the treatment of human monocytes with an aluminum-based adjuvant resulted in the release of inflammatory factors and proteolytic enzymes into the extracellular microenvironment, which have been shown to be involved in some human diseases (Ligi et al. 2015). It is obvious that new generation of adjuvants should be at least as potent as the TLR agonists, but they should exhibit significantly lower systemic toxicity and should be conjugable to a delivery platform.

\section{Synthetic polymer vaccines}

The call for safer and more efficient vaccines with long-term effects has led scientists to the idea to of combining peptide- or (glyco)protein-based antigens (and adjuvants) with biocompatible polymer carriers that are successfully used for drug or gene delivery. A major advantage for the preparation of such polymer vaccines was that the increased size and molecular weight of the resulting vaccine to physically restrict antigen and adjuvant biodistribution would prevent its systemic toxicity and also prolong local immune activation at the injection site, as long-term release results in more robust immune responses. In addition, attachment of an antigen and an adjuvant to a multivalent polymer carrier increases the avidity between the vaccine and appropriate receptors on immune cells, as the resulting polymer vaccine structure better mimics the repeating active site motifs on natural pathogens. The co-delivery of an antigen and adjuvant also possesses other benefits (Blander et al. 2006, Nair-Gupta et al. 2014). Last but not least, 
incorporation of usually hydrophobic adjuvants to the structure of the water soluble polymers improves their solubility, which enables the use of higher doses of adjuvants.

In most commercial vaccines, the antigens and adjuvants are administered as an aqueous solution of single components. In polymer vaccines, both antigens and adjuvants are either covalently attached to a biocompatible polymer carrier or encapsulated in polymer particles. Below, the most widely used synthetic polymer carriers for vaccine delivery are described (Fig. 3).

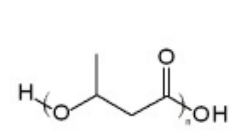

poly(hydroxybutyrate)<smiles>CC(O)CNC(=O)C(C)(C)C</smiles>

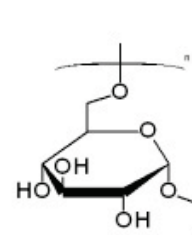

poly( $\mathrm{N}$-(2-hydroxypropyl) methacrylamide)<smiles>COOC(=O)OC(C)C(C)=O</smiles>

poly(L,D-lactic-co-glycolic acid)<smiles>C=CC(C)=O</smiles>

poly(ethylene glycol)-block-poly(propylene sulfide)

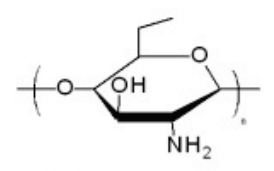

chitosan

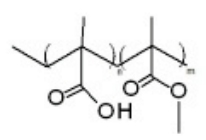

Eudragit L100<smiles>CCCN(CCN(C)C(C)=O)C(C)=O</smiles>

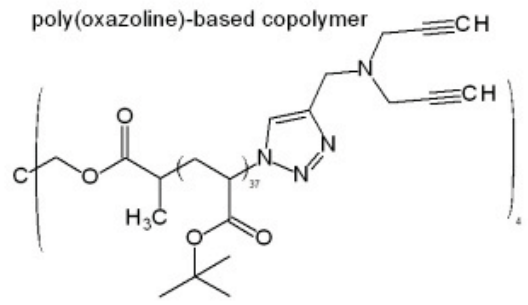

poly(tert-butyl acrylate)-based polymer

Fig. 3. Synthetic or natural macromolecular carriers described in this review.

One of the most widely studied biodegradable synthetic polymers for vaccine delivery is poly(lactic acid) (PLA) and poly(lactic-co-glycolic acid) (PLGA). Baxendale et al. used an interesting approach to prepare poly(D,L-lactic acid) (10,000-18,000 g/mol) microparticles mixed with the tetanus toxoid (TT), creating a single-shot vaccine. This process, called NanoMix ${ }^{\mathrm{TM}}$, is solvent-free and uses $\mathrm{CO}_{2}$ in supercritical state, which dissolves in the polymer and lowers its glass transition temperature (the transition between brittle glass and a rubber-like state), causing the polymer to liquefy. The dry powdered TT was mixed with the liquefied polymer at ambient temperature, and the mixture was pressed through a nozzle to create irregular and porous microparticles with a mean diameter of $22.8 \mu \mathrm{m}$. The TT content, determined by acetonitrile extraction, was 
$6.3 \mu \mathrm{g} / \mathrm{mg}$ microparticles with a loading efficiency of $78 \%$ (Baxendale et al. 2011). The in vitro release study ( $0.01 \%$ Tween $20,0.01 \%$ sodium azide in PBS) showed that most of the TT was probably physically adsorbed to the surface of the polymer because most of the TT (75\%) was released in the first day. Afterwards, the TT release was almost constant. However, it is preferable to create an antigen delivery system serving as a depot from which the antigen is released gradually. Nevertheless, the singleshot vaccine was found to be as effective as three doses of a commercial tetanus vaccine containing TT adsorbed to an aluminum adjuvant (5 months after the administration). Interestingly, adding alum to the TT-microparticles did not increase the production of IgG antibodies in vivo, as was shown in previous publications (Singh et al. 1998).

Rajapaksa et al. (2010) prepared submicronsized PLGA $(50,000-75,000 \mathrm{~g} / \mathrm{mol})$ particles as a carrier for the recombinant protein influenza hemagglutinin and targeting peptide Clostridium perfringens enterotoxin (CPE) as the model for an oral/intranasal vaccine against influenza A. The therapy focused on targeting the M cells present in the mucosal epithelium of the gastrointestinal tract, the main function of which is the endocytosis of antigens that are transported to intraepithelial macrophages and lymphocytes, which then migrate to lymph nodes. PLGA particles of approximately $450 \mathrm{~nm}$ and with protein loading of $2 \mathrm{wt} \%$ were prepared via a solvent evaporation/double emulsion method. CPE substantially facilitated uptake by the $M$ cells (in nasalassociated lymphoid tissue and Peyer's patches). The study showed that toxin release gradually increased (14\% in six weeks) (Rajapaksa et al. 2010).

Oral vaccines have to be designed to protect the protein antigen from the acidic $\mathrm{pH}$ of the stomach because its target destination is the mucosal epithelium in the small intestine. Usually, the antigen is encapsulated in a polymer matrix or in particles using the double emulsion method (Singh et al. 2015). For the preparation of a vaccine against swine dysentery containing a membrane protein of the pathogenic intestinal spirochete Brachyspira hyodysenteriae, commercially available Eudragit L 100 was used. Eudragit L 100 is an anionic copolymer based on methacrylic acid and methyl methacrylate with molecular weight of approximately $125,000 \mathrm{~g} / \mathrm{mol}$. The Eudragit forms particles that are insoluble under acidic conditions and that dissolve at a $\mathrm{pH}$ above 6 , so they release the loaded antigen in the intestine. To improve its mucoadhesive properties, the authors thiolated Eudragit with L-cysteine hydrochloride. Microparticles with diameters ranging from 1-10 $\mu \mathrm{m}$ were loaded up to $18 \mathrm{wt} \%$ with the antigen. It was shown that the thiolation of the Eudragit elicited higher production of mucosal IgA and serum IgG antibodies and facilitated effective uptake of microparticles by Peyer's patches through the intestinal mucosa. The vaccine induced CD4 $+\mathrm{T}$ cell immune responses and also elicited strong CD8+ $\mathrm{T}$ cell responses.

Another biocompatible polymer that is potentially suitable for vaccine delivery is poly(oxazoline). Farkaš and co-workers synthesized a linear poly(oxazoline)-based copolymer with a molecular weight $21,100 \mathrm{~g} / \mathrm{mol}$. The copolymer comprised $20 \mathrm{~mol} \%$ of comonomer units with primary amino groups, which were consequently reacted with the carboxylic group of an immunogenic protein, bovine serum albumin (BSA). The coupling reagent 4-(4,6dimethoxy-1,3,5-triazin-2-yl)-4-methylmorpholinium chloride was used to activate the carboxylic groups of the protein. The BSA content in the copolymer was up to $60 \%$. The next step was the attachment of an antigen, detoxified lipopolysaccharide $\left(5 \%\right.$ acetic acid, $\left.105^{\circ} \mathrm{C}\right)$ from Vibrio cholerae $\mathrm{O} 135$, to the remaining free amino groups. The keto group of the antigen reacted with the free amino groups of the polymer carrier by reductive amination catalyzed by $\mathrm{Na}\left(\mathrm{BH}_{3}\right) \mathrm{CN}$. The only preliminary immunological test in vivo showed significantly increased IgG levels in comparison with a BSA-antigen conjugate after three immunizations (Farkas et al. 2010). This demonstrated that the vaccine could induce humoral immunity; however, a study to prove that the vaccine can induce a cellular immune response should be performed.

An anticancer vaccine based on poly(acrylate) was prepared by Liu et al. (2015a, b). The polymer carriers were synthesized via atom-transfer radical polyme-rization. Four poly(t-butyl acrylate) polymers, two linear $(\mathrm{MW} \sim 5,000 \mathrm{~g} / \mathrm{mol})$ and two star-shaped (MW 10,000 g/mol), differing in the number of end alkyne groups $(1,2,4$, and 8$)$, were coupled with an azide functionalized antigen via a Cu-catalyzed azide-alkyne click reaction. As an antigen, a peptide epitope 8Qmin (consisting of 14 amino acids) derived from human papillomavirus type 16 oncoprotein was chosen because it contains CD8+ and CD4+ epitopes, which are widely expressed on $\mathrm{T}$-helper cells and cytotoxic $\mathrm{T}$ cells. The activation of $\mathrm{CD} 8+$ and $\mathrm{CD} 4+$ cells was previously correlated with a reduction of a tumor growth. The yield of the conjugation reaction of the antigen to the polymer 
carrier was $76-98 \%$. The conjugates self-assembled in PBS to form $12-17 \mu \mathrm{m}$ (depending on the polymer structure) particles with a narrow size distribution. It was demonstrated that the covalent conjugate of the polymer and the antigen induced a higher immune response than the antigen emulsified in adjuvant (mineral oil Montanide ISA51) The polymer vaccine also activated CD8+ and CD4+ cells and contributed to stopping the tumor growth (Liu et al. 2015a, b).

A polyethylenimine-based (PEI) vaccine for intranasal applications, proposed by Li et al. (2016), was synthesized by a partial crosslinking of low-molecularweight linear PEI (MW=2,000 g/mol) with diethylene glycol activated using nitrophenyl chloroformate. The molecular weight of the resulting polymer carrier was $30,000 \mathrm{~g} / \mathrm{mol}$. Some of the unreacted amino groups in the PEI chain were used for the covalent attachment of adjuvant: the toll-like receptor 4 agonist (TLR-4a) heptapeptide RS09 (Shanmugam et al. 2012). The adjuvant was linked to the polymer carrier through the $\mathrm{N}$ succinimidyl-3-(2-pyridyldithio)propionate spacer. Afterwards, the PEI-RS09 conjugate was mixed with antigen, the recombinant adenovirus serotype-5 encoding HIV gag protein, to form an electrostatic complex of approximately $190 \mathrm{~nm}$ in diameter. It was documented that the uptake of the conjugate by dendritic cells was almost two times higher in the presence of RS09 adjuvant than without RS09, while the T-cell response and production of cytokines (IFN- $\gamma$, IL-4) were not significantly influenced by the presence of RS09 on the polymer. It was also shown that the PEI-HIV gag conjugate triggered the secretion of $\operatorname{IgA}$ in nasal and vaginal wash; the level of secretion was comparable to that of the naked adenovirus and the adenovirus coated with the PEI but was augmented two-fold in the presence of RS09. However, RSO9 showed no effect on improving the secretion of specific humoral IgG antibodies.

A biocompatible polymer based on N-(2hydroxypropyl)methacrylamide (HPMA), commonly used as a drug carrier (Kopecek et al. 1985), was covalently linked with a TLR-7/8a adjuvant based on imidazoqunoline, and the immunogenicity and physicochemical properties were tested (Lynn et al. 2015). Various polymer-adjuvant conjugates differing in hydrophobicity (alkane vs. PEG side chains) and the density of TLR-7/8a (1-10 mol\%) arrayed along the poly(HPMA) backbone were tested. It was shown that the polymer-adjuvant conjugates changed their morphology with increasing adjuvant density from random coils
(1-4 mol\% of TLR-7/8a) to sub-micron-sized particles (8-10 mol\% of TLR-7/8a) approximately $700 \mathrm{~nm}$ in diameter. Probably because of the particle formation, the production of lymph node cytokines (IP-10 and IL-12p40) was considerably higher than with the use of single TLR-7/8a molecules or poly(HPMA) with low adjuvant density forming random coils. The polymer particles were admixed with the model antigen ovalbumin to test the CD8+ $\mathrm{T}$ cell response. It was substantially higher in the case of the polymer particles (10 mol\% of TLR-7/8a) than with ovalbumin alone or poly(HPMA) with a lower concentration of the adjuvant.

Lynn et al. (2015) also prepared an amphiphilic diblock copolymer composed of hydrophilic poly(HPMA) and poly(diethylene glycol methacrylate) thermoresponsive blocks that assembles into defined polymer particles $(2,000 \mathrm{~nm})$ after the attachment of TLR-7/8a and the recombinant HIV Gag protein antigen at body temperature. TLR-7/8a was attached to the polymer by covalent bonds and HIV Gag protein through coil-coil interaction (Pechar et al. 2014). Co-delivery of the antigen and adjuvant significantly enhanced $\mathrm{T}$ cell and antibody responses. This method could be favorable for any type of peptide antigens.

A polymer similar to HPMA in the context of its biocompatibility and hydrophilicity is poly(glycerol monomethacrylate) (PGMMA). Polymers of PGMMA of various molecular weights $(5,300-9,700 \mathrm{~g} / \mathrm{mol})$ were synthesized via controlled radical polymerization (atom transfer radical polymerization) (Ragupathy et al. 2014). The hydroxyl groups of the polymer were acylated with acryloyl chloride to introduce double bonds and afterwards reacted with thiomanose via Michael-type addition. The thiomanose activates the complement system and is recognized by mannose receptors on APC. The alkyne end groups of the polymer originating from the initiator propargyl 2-bromoisobutyrate were reacted with azide groups of a fluorophore via $\mathrm{Cu}$ catalyzed click reaction. The conjugates passed cytotoxicity tests and underwent in vitro tests of TNF $\alpha$ cytokine expression by bone marrow-derived dendritic cells. The polymerthiomannose conjugate with $40 \mathrm{~mol} \%$ of thiomannose elicited a higher TNF $\alpha$ response than the conjugate with $24 \mathrm{~mol} \%$ of thiomannose. The conjugates were compared with a commercially available mannan that induced an almost three times higher cytokine response. The authors suggest the universal utilization of the PGMMA carrier for different antigens, but the production process comprises many steps, and the antigens have to contain 
a thiol group.

Scott et al. (2012) prepared an interesting antigen delivery system based on poly(ethylene glycol)block-poly(propylene sulfide) polymersomes (Scott et al. 2012). The living polymerization of hydrophobic propylene sulfide was initiated with benzyl mercaptan. Afterwards, the sulfide end group of the polymer chain reacted with mesylated poly(ethylene glycol) (PEG). The weight fraction of PEG was $0.28 \%$. Polymersomes, spherical particles with hydrophilic cavity were loaded with ovalbumin (antigen) or gardiquimod or TLR7/8 agonist resiquimod (adjuvants). The block copolymer formed a thin film and was rehydrated in PBS solution of ovalbumin or gardiquimod or resiquimod. The antigen loading was $5 \mu \mathrm{g} / \mathrm{mg}$ of polymersome. The antigen was released in $72 \mathrm{~h}$ in the presence of hydrogen peroxide. Ovalbumine loaded polymersomes induced approximately two times higher CD8+ T cells response (release IFN- $\gamma$ ) in each proliferation cycle in vitro and gardiquimod loaded in polymersome induced 10fold higher production of proinflammatory cytokines IL- 6 and IL-12 than free gardiquimod.

\section{Natural polymer vaccines}

Aside from the abovementioned synthetic biocompatible polymers, natural polymers may also serve as antigen (or adjuvant) carriers. For example, poly((R)3-hydroxybutyrate) (PHB), belonging to polyesters, which can be produced synthetically or by various bacteria as storage material, is a good candidate for vaccine delivery. Spherical PHB beads (50-150 nm) displaying Hepatitis $\mathrm{C}$ core antigen $(\mathrm{HCc})$ on their surface, produced by the genetically modified bacterium Lactococcus lactis, were used for the preparation of Hepatitis C vaccine (Parlane et al. 2011). Previously, Escherichia coli (E. coli) had been used for production of PHB beads with surface antigens derived from bacterium Mycobacterium tuberculosis (Parida et al. 2010), but in this case, the use of Lactococcus lactis was more advantageous because there was no need to remove lipopolysaccharides, which are coproduced by E. coli. The removal of lipopolysaccharides is costly and may destroy possible surface antigens on the polymer beads. The PHB beads displaying HCc were mixed with the oilin-water adjuvant Emulsigen, and a recombinant Hepatitis $\mathrm{C}$ virus (recHCc) emulsified in complete Freund's adjuvant (CFA) and PHB produced by E. coli were used as controls. The production of cytokines (IFN- $\gamma$, IL- 6 , etc.) after 3 vaccinations of female $\mathrm{C} 57 \mathrm{BL} / 6$ mice was elevated in the case of PHB beads displaying HCc produced by $\mathrm{E}$. coli in comparison with cytokine production after vaccination with $\mathrm{PHB}$ beads displaying HCc produced by Lactococcus lactis, and the most increased cytokine production was induced by recHCc in CFA. Unfortunately, CFA cannot be used in humans because of severe site reactions. Serum $\operatorname{IgG} 1$ and $\operatorname{IgG} 2$ responses towards $\mathrm{PHB}$ beads displaying $\mathrm{HCc}$ were not significant. The authors, however, claim that the humoral response may not be so important for vaccines against viruses. Nevertheless, the production of PHB beads by Lactococcus lactis or E. coli is an elegant way to prepare antiviral vaccines.

ISCOM (immunostimulating complex) is a broadly used adjuvant/delivery system in veterinary vaccines and is commercially available. The matrix of ISCOM, composed of saponin (extracted from the Quillaja saponaria Molina tree), phospholipids, and cholesterol, forms micelles in water that may contain bacterial and viral proteins in their hydrophobic cavity (Morein et al. 1984). Pandey and Dixit prepared ISCOM micelles (44 nm) with the hepatitis B protein at a loading efficiency of $39 \%$. The immunological effect of the vaccine was compared with that of a formulation composed of alum adsorbed on hepatitis B, administered s.c.. Both vaccines showed a comparable result in terms of eliciting a humoral response (antibodies $\mathrm{IgG}$ ), but the ISCOM vaccine generated almost three times more released cytokines (IFN- $\gamma$, IL-2) than the alum-based vaccine, which is a measure of $\mathrm{T}$ cell responses. Moreover, the advantage of the ISCOM vaccine was in the intranasal administration in the contrast to subcutaneous injection of the alum-based vaccine (Pandey et al. 2009).

Elliasson et al. (2011) combined ISCOM with the A1 subunit from cholera toxin and a dimer of the Dfragment of Staphylococcus aureus (CTA1-DD) as the adjuvants. Immunological tests proved that the mixture of both adjuvants was less toxic and more potent than the individual adjuvants administered separately. Next, they incorporated the M2e-peptide from the influenza A virus into the ISCOM matrix in the form of a fusion peptide with the CTA1-DD protein. The vector elicited strong serum anti-M2e antibodies of both IgG1 and $\operatorname{IgG} 2$ a type, and a strong effect was observed on specific IgA stimulation. Mice vaccinated with controlled vaccines without the M2e-peptide did not exhibit production of any antibodies. Moreover, the ISCOM/CTA1-DD 
adjuvant was concurrently intranasally administered to mice with a whole cell antigen from the influenza virus (PR8) or a tetanus toxoid. Both vaccines elicited ten times higher production of serum IgG antibodies than antigens with ISCOM alone or CTA1-DD alone, and the vaccine containing PR8 elicited approximately two times higher production of cytokines (IFN- $\gamma$, IL-4-6) in vivo. This type of combined adjuvant (ISCOM/CTA1-DD) could be used as a universal base for admixing any antigens. The storage of the vaccine is very important for practical use, and it was shown that the vaccine could be stored for one year at $4{ }^{\circ} \mathrm{C}$ without diminished properties (Eliasson et al. 2011).

Chitosan is a linear polysaccharide composed of D-glucosamine. It occurs naturally in the shells of crustaceans and is used in many applications, e.g. water treatment because of its high affinity for heavy metals (Vunain et al. 2016) or for drug delivery (Agnihotri et al. 2004). Prego et al. (2010) prepared chitosan-based nanoparticles loaded with recombinant hepatitis B surface antigen. Particles of 160-200 nm were formed by mixing a positively charged chitosan with the anionic crosslinker sodium tripolyphosphate and the antigen. The antigen loading was $1.5 \mathrm{wt} \%$, with $60 \%$ recovery. An in vitro release study (water containing thimerosal) showed that $100 \%$ of the antigen was released from the nanoparticles in 14 days. The immunogenicity of the chitosan/hepatitis B surface antigen vaccine was compared with that of alum-adsorbed hepatitis B antigen. The studies showed that chitosan nanoparticles induced nine times higher IgG secretion 103 days after an intramuscular immunization than the alum-based vaccine. Additionally, the stability of the chitosan nanoparticles was verified; their immunogenic properties were not changed after storage as an aqueous suspension in a refrigerator $\left(4^{\circ} \mathrm{C}\right)$ for three months or as a freezedried form (Prego et al. 2010).

A Swedish company, Viscogel AB, developed the chitosan-based hydrogel adjuvant ViscoGel ${ }^{\mathrm{TM}}$. The biodegradable hydrogel is $99 \%$ water and contains $1 \%$ of deacetylated crosslinked chitosan, which can be processed into defined particles. In phase I/IIa clinical trials, the hydrogel was mixed with a registered ActHIB ${ }^{\circledR}$ influenza vaccine (Haemophilius influenzae type B) (Neimert-Andersson et al. 2014). It was demonstrated that the ViscoGel-based vaccine slightly increased cellular immune responses (titers of cytokine IFN- $\gamma$ ) in comparison with the Act-HIB ${ }^{\circledR}$ vaccine alone. The evaluation of the immunostimulatory effect of the
ViscoGel adjuvant was complicated by the huge heterogeneity of antibody titers on the day of vaccination (day 0). In this trial, ViscoGel was not found to be able to elicit a strong humoral immune response. However, in comparison with aluminum-based adjuvants, the ViscoGel proved to be safe and tolerated by the patients.

Another polysaccharide, acetylated dextran, was used by Schully et al. (2015) for the preparation of an anti-melioidosis vaccine. Melioidosis is an infectious disease caused by the bacterium Burkholderia pseudomallei. Hollow porous microparticles formed by acetylated dextran $(10,000$ or $71,000 \mathrm{~g} / \mathrm{mol})$ and filled with a whole-cell lysate of $B$. pseudomallei and the resiquimod adjuvant (TLR7/8 agonist) were prepared. Microparticles (MPs) $600 \mathrm{~nm}$ in diameter were loaded with $13.4 \mu \mathrm{g} / \mathrm{mg}$ lysate. Laboratory mice were vaccinated twice with vaccines containing a mixture of lysate, dextran MPs, resiquimod, and alum and after 14 days, were infected with a B. pseudomallei strain. The control mice (vaccinated with PBS or empty dextran MPs) died almost immediately $(96 \%$ at two days after the challenge). The survival rate of mice immunized with free lysate mixed with MPs encapsulating resiquimod and the survival rate of mice immunized with MPs encapsulating resiquimod in combination with MPs encapsulating the lysate were comparable and were substantially higher than the survival rates of mice immunized with lysate or resiquimod separately. The IgG titers increased after the vaccination in contrast to the control (PBS); however, the IgG level did not depend on the form of lysate (free or encapsulated in MPs) or the added alum. On the other hand, the encapsulated adjuvant in MPs mixed with lysate encapsulated in MPs induced a higher cellular response (production of cytokines IL-4, IL-5, IFN- $\gamma$, etc.) than free lysate mixed with resiquimod encapsulated in MPs (with or without alum) (Schully et al. 2015).

\section{Non-polymer vaccines}

Other than the polymer-based vaccines, nondegradable inorganic materials are also used as antigen or adjuvant carriers. For example, gold nanoparticles (GNPs) synthesized by Chen et al. (2010) were conjugated with a peptide sequence from the foot-andmouth disease virus VP1 protein. The GNPs possess a strong affinity to sulfhydryl groups, which were used for conjugation of the peptide containing a cysteine residue at the end of the chain. Batches of nanoparticles varied in 
size from 2-50 $\mathrm{nm}$ in diameter, and the loading of the antigen was proportional to their surface area. The immune response was monitored for ten weeks after vaccination of the mice. The highest antibody (IgG) response was observed with the nanoparticles containing an attached VP1 peptide in contrast to the antigen conjugated to a commercial toxoid keyhole limpet hemocyanine. The gold nanoparticles themselves did not elicit any antibody production. It was found that the immune response was size-dependent, with an optimal nanoparticle diameter of 8-17 nm (Chen et al. 2010). The advantage of gold nanoparticles is their biocompatibility, stability in solution, and ability to be prepared with defined particle sizes.

Another example of a non-polymer nanomaterial used in medical applications is carbon. Carbon nanoparticles (CNs) were synthesized using silica particles as a template and sucrose as a carbon source (Wang et al. 2011). After carbonization at $900{ }^{\circ} \mathrm{C}$, the silica template was removed with hydrofluoric acid. The CNs were monodisperse, with diameters of $470 \mathrm{~nm}$, and contained mostly 40-60 nm pores. The CNs were loaded with $79 \mu \mathrm{g} / \mathrm{mg}$ particles of a model antigen, bovine serum albumin (BSA). The antigen is "hidden" inside the pores of the nanoparticles, which are not affected by the acidic conditions in the gastrointestinal tract. One group of Balb/c mice was immunized orally with the CNs loaded with BSA, the second group was immunized orally with BSA alone, and the third group was vaccinated intramuscularly with BSA emulsified in CFA. The IgG production induced by the BSA loaded in $\mathrm{CNs}$ and by the BSA emulsified in CFA was comparable; however, the IgA level in the intestinal, salivary, and vaginal secretions was three times higher after immunization with BSA/CNs than after use of BSA in CFA. BSA alone elicited only a negligible amount of antibodies. It was thus demonstrated that carbon nanoparticles can serve as an antigen carrier for oral vaccines and can induce both serum (systemic) and mucosal immunity.

\section{Conclusions}

Vaccination is considered one of the ten greatest public health achievements of the USA in the 20th century (CDC 1999). Because of vaccination technology, we do not have to fear fatal infectious diseases, such as smallpox, measles, polio, diphtheria, pertussis, or varicella, not to mention the enormous savings in healthcare costs. Despite this, public confidence in vaccines is hesitant (Siddiqui et al. 2013). Although vaccines may have some adverse side effects, the advantages of vaccination are indisputable.

Current research on immunology and vaccines is occupied with the preparation of safer and more efficient vaccines for infectious diseases and focuses on cancer or Alzheimer's disease prevention. In particular, particlebased or macromolecular vaccines conjugated to potent adjuvants are promising delivery systems.

\section{Conflict of Interest}

There is no conflict of interest.

\section{Acknowledgements}

This work was supported by the Ministry of Education, Youth and Sports of CR within the National Sustainability Program II (Project BIOCEV-FAR LQ1604).

\section{References}

AGNIHOTRI SA, MALLIKARJUNA NN, AMINABHAVI TM: Recent advances on chitosan-based micro- and nanoparticles in drug delivery. $J$ Control Release 100: 5-28, 2004.

AI C, ZHANG Q, DING J, REN C, WANG G, LIU X, TIAN F, ZHAO J, ZHANG H, CHEN YQ, CHEN W: Suppression of dust mite allergy by mucosal delivery of a hypoallergenic derivative in a mouse model. Appl Microbiol Biot 99: 4309-4319, 2015.

ANDERSON RJ, SCHNEIDER J: Plasmid DNA and viral vector-based vaccines for the treatment of cancer. Vaccine 25: B24-B34, 2007.

APPAIAHGARI MB, VRATI S: IMOJEV(®): A yellow fever virus-based novel Japanese encephalitis vaccine. Expert Rev Vaccines 9: 1371-1384, 2010.

AWATE S, BABIUK LA, MUTWIRI G: Mechanisms of action of adjuvants. Front Immunol 4: 114, 2013.

BAXENDALE A, VAN HOOFF P, DURRANT LG, SPENDLOVE I, HOWDLE SM, WOODS HM, WHITAKER MJ, DAVIES OR, NAYLOR A, LEWIS AL, ILLUM L: Single shot tetanus vaccine manufactured by a supercritical fluid encapsulation technology. Int J Pharm 413: 147-154, 2011. 
BLANDER JM, MEDZHITOV R: Toll-dependent selection of microbial antigens for presentation by dendritic cells. Nature 440: 808-812, 2006.

BRITO LA, O'HAGAN DT: Designing and building the next generation of improved vaccine adjuvants. J Control Release 190: 563-579, 2014.

BRUBAKER CE, PANAGIOTOU V, DEMURTAS D, BONNER DK, SWARTZ MA, HUBBELL JA: A cationic micelle complex improves $\mathrm{CD} 8+\mathrm{T}$ cell responses in vaccination against unmodified protein antigen. $A C S$ Biomater Sci Eng 2: 231-240, 2016.

CASALE TB, STOKES JR: Immunotherapy: What lies beyond. J Allergy Clin Immun 133: 612-619, 2014.

CDC: Ten great public health achievements--United States, 1900-1999. MMWR. Morbidity and mortality weekly report 48, 1999.

CHEN Y-S, HUNG Y-C, LIN W-H, HUANG GS: Assessment of gold nanoparticles as a size-dependent vaccine carrier for enhancing the antibody response against synthetic foot-and-mouth disease virus peptide. Nanotechnology 21: $195101,2010$.

ELIASSON DG, HELGEBY A, SCHON K, NYGREN C, EL-BAKKOURI K, FIERS W, SAELENS X, LOVGREN KB, NYSTROM I, LYCKE NY: A novel non-toxic combined CTA1-DD and ISCOMS adjuvant vector for effective mucosal immunization against influenza virus. Vaccine 29: 3951-3961, 2011.

FARKAS P, KORCOVA J, KRONEK J, BYSTRICKY S: Preparation of synthetic polyoxazoline based carrier and Vibrio cholerae O-specific polysaccharide conjugate vaccine. Eur J Med Chem 45: 795-799, 2010.

HEUKING S, ADAM-MALPEL S, SUBLET E, IANNITELLI A, DI STEFANO A, BORCHARD G: Stimulation of human macrophages (THP-1) using Toll-like receptor-2 (TLR-2) agonist decorated nanocarriers. J Drug Target 17: 662-670, 2009.

JAGANATHAN KS, VYAS SP: Strong systemic and mucosal immune responses to surface-modified PLGA microspheres containing recombinant Hepatitis B antigen administered intranasally. Vaccine 24: 4201-4211, 2006.

KALLEN K-J, HEIDENREICH R, SCHNEE M, PETSCH B, SCHLAKE T, THESS A, BAUMHOF P, SCHEEL B, KOCH SD, FOTIN-MLECZEK M: A novel, disruptive vaccination technology. Hum Vaccin Immunother 9: 2263-2276, 2013.

KOPECEK J, REJMANOVA P, DUNCAN R, LLOYD JB: Controlled release of drug model from N-(2-hydroxypropyl)methacrylamide copolymers. Ann N Y Acad Sci 446: 93-104, 1985.

KUTZLER MA, WEINER DB: DNA vaccines: ready for prime time? Nat Rev Genet 9: 776-788, 2008.

LI M, JIANG Y, GONG T, ZHANG Z, SUN X: Intranasal vaccination against HIV-1 with adenoviral vector-based nanocomplex using synthetic TLR-4 agonist peptide as adjuvant. Mol Pharm 13: 885-894, 2016.

LIGI D, SANTI M, CROCE L, MANNELLO F: Aluminum induces inflammatory and proteolytic alterations in human monocytic cell line. J Inorg Biochem 152: 190-198, 2015.

LIU TY, GIDDAM AK, HUSSEIN WM, JIA ZF, MCMILLAN NAJ, MONTEIRO MJ, TOTH I, SKWARCZYNSKI M: Self-adjuvanting therapeutic peptide-based vaccine induce CD8(+) cytotoxic $\mathrm{T}$ lymphocyte responses in a murine human papillomavirus tumor model. Curr Drug Deliv 12: 3-8, 2015 a.

LIU TY, HUSSEIN WM, GIDDAM AK, JIA Z, REIMAN JM, ZAMAN M, MCMILLAN NA, GOOD MF, MONTEIRO MJ, TOTH I, SKWARCZYNSKI M: Polyacrylate-based delivery system for self-adjuvanting anticancer peptide vaccine. $J$ Med Chem 58: 888-896, 2015 b.

LYNN GM, LAGA R, DARRAH PA, ISHIZUKA AS, BALACI AJ, DULCEY AE, PECHAR M, POLA R, GERNER MY, YAMAMOTO A, BUECHLER CR, QUINN KM, SMELKINSON MG, VANEK O, CAWOOD R ET AL.: In vivo characterization of the physicochemical properties of polymer-linked TLR agonists that enhance vaccine immunogenicity. Nat Biotechnol 33: 1201-1210, 2015.

MAUBANT S, BANISSI C, BECK S, CHAUVAT A, CARPENTIER AF: Adjuvant properties of cytosine-phosphateguanosine oligodeoxynucleotide in combination with various polycations in an ovalbumin-vaccine model. Nucleic Acid Ther 21: 231-240, 2011.

MITTENDORF EA, HOLMES JP, PONNIAH S, PEOPLES GE: The E75 HER2/neu peptide vaccine. Cancer Immunol Immunother 57: 1511-1521, 2008. 
MOREIN B, SUNDQUIST B, HOGLUND S, DALSGAARD K, OSTERHAUS A: ISCOM, a novel structure for antigenic presentation of membrane-proteins from enveloped viruses. Nature 308: 457-460, 1984.

MOVAHEDI Z, MOGHADAM PS, SEPAHI MA, HEYDARI H, DOUST MA, SHOKROLLAHI MR, SAADATI A, MOHAMMADI MM, NAZAR NSB: The vaccine adverse event in children and infants hospitalized to children hospital. J Curr Res Sci 3: 106-109, 2015.

NAIR-GUPTA P, BACCARINI A, TUNG N, SEYFFER F, FLOREY O, HUANG Y, BANERJEE M, OVERHOLTZER M, ROCHE PA, TAMPE R, BROWN BD, AMSEN D, WHITEHEART SW, BLANDER JM: TLR signals induce phagosomal MHC-I delivery from the endosomal recycling compartment to allow cross-presentation. Cell 158: 506-521, 2014.

NEIMERT-ANDERSSON T, BINNMYR J, ENOKSSON M, LANGEBACK J, ZETTERGREN L, HALLGREN AC, FRANZEN H, LIND ENOKSSON S, LAFOLIE P, LINDBERG A, AL-TAWIL N, ANDERSSON M, SINGER P, GRONLUND H, GAFVELIN G: Evaluation of safety and efficacy as an adjuvant for the chitosanbased vaccine delivery vehicle ViscoGel in a single-blind randomised Phase I/IIa clinical trial. Vaccine 32: 5967-5974, 2014.

PANDEY RS, DIXIT VK: Evaluation of ISCOM vaccines for mucosal immunization against hepatitis B. J Drug Target 18: 282-291, 2009.

PARIDA SK, KAUFMANN SHE: Novel tuberculosis vaccines on the horizon. Curr Opin Immunol 22: 374-384, 2010.

PARLANE NA, GRAGE K, LEE JW, BUDDLE BM, DENIS M, REHM BHA: Production of a particulate Hepatitis C vaccine candidate by an engineered lactococcus lactis strain. Appl Environ Microbiol 77: 8516-8522, 2011.

PASQUALE AD, PREISS S, SILVA FT, GARCON N: Vaccine adjuvants: from 1920 to 2015 and beyond. Vaccines 3: 320-343, 2015.

PECHAR M, POLA R, LAGA R, BRAUNOVA A, FILIPPOV SK, BOGOMOLOVA A, BEDNAROVA L, VANEK O, ULBRICH K: Coiled coil peptides and polymer-peptide conjugates: synthesis, self-assembly, characterization and potential in drug delivery systems. Biomacromolecules 15: 2590-2599, 2014.

PODDA A, DEL GIUDICE G: MF59-adjuvanted vaccines: increased immunogenicity with an optimal safety profile. Expert Rev Vaccines 2: 197-203, 2003.

PREGO C, PAOLICELLI P, DIAZ B, VICENTE S, SANCHEZ A, GONZALEZ-FERNANDEZ A, JOSE ALONSO M: Chitosan-based nanoparticles for improving immunization against hepatitis B infection. Vaccine 28: 26072614, 2010.

RAGUPATHY L, MILLAR DG, TIRELLI N, CELLESI F: An orthogonal click-chemistry approach to design poly(glycerol monomethacrylate)-based nanomaterials for controlled immunostimulation. Macromol Biosci 14: 1528-1538, 2014.

RAJAPAKSA TE, STOVER-HAMER M, FERNANDEZ X, ECKELHOEFER HA, LO DD: Claudin 4-targeted protein incorporated into PLGA nanoparticles can mediate M cell targeted delivery. J Control Release 142: 196-205, 2010.

ROUSH SW, MURPHY TV, VACCINE PREVENTABLE DIS T: Historical comparisons of morbidity and mortality for vaccine-preventable diseases in the United States. J Am Med Assoc 298: 2155-2163, 2007.

SAADE F, PETROVSKY N: Technologies for enhanced efficacy of DNA vaccines. Expert Rev Vaccines 11: 189-209, 2012.

SAINI V, VERMA SK, MURTHY PK, KOHLI D: Poly(D,L)-lactide-co-glycolide (PLGA) microspheres as immunoadjuvant for Brugia malayi antigens. Vaccine 31: 4183-4191, 2013.

SCOTT EA, STANO A, GILLARD M, MAIO-LIU AC, SWARTZ MA, HUBBELL JA: Dendritic cell activation and T cell priming with adjuvant- and antigen-loaded oxidation-sensitive polymersomes. Biomaterials 33: 6211$6219,2012$.

SHANMUGAM A, RAJORIA S, GEORGE AL, MITTELMAN A, SURIANO R, TIWARI RK: Synthetic toll like receptor-4 (TLR-4) agonist peptides as a novel class of adjuvants. Plos One 7: e30839, 2012.

SCHIJNS V: Immunological concepts of vaccine adjuvant activity - Commentary. Curr Opin Immunol 12: 456-463, 2000.

SCHULLY KL, BELL MG, PROUTY AM, GALLOVIC MD, GAUTAM S, PEINE KJ, SHARMA S, BACHELDER EM, PESCE JT, ELBERSON MA, AINSLIE KM, KEANE-MYERS A: Evaluation of a biodegradable 
microparticulate polymer as a carrier for Burkholderia pseudomallei subunit vaccines in a mouse model of melioidosis. Int J Pharm 495: 849-861, 2015.

SIDDIQUI M, SALMON DA, OMER SB: Epidemiology of vaccine hesitancy in the United States. Hum Vaccin Immunother 9: 2643-2648, 2013.

SILVERS MJ, STEPTOE MM: Historical overview of vaccines. Prim Care 28: 685-695, 2001.

SINGH B, MAHARJAN S, JIANG T, KANG S-K, CHOI Y-J, CHO C-S: Combinatorial approach of antigen delivery using $\mathrm{m}$ cell-homing peptide and mucoadhesive vehicle to enhance the efficacy of oral vaccine. Mol Pharm 12: 3816-3828, 2015.

SINGH M, LI XM, WANG HY, MCGEE JP, ZAMB T, KOFF W, WANG CY, O'HAGAN DT: Controlled release microparticles as a single dose diphtheria toxoid vaccine: immunogenicity in small animal models. Vaccine 16: 346-352, 1998.

SUKSAMRAN T, OPANASOPIT P, ROJANARATA T, NGAWHIRUNPAT T: Development of Alginate/Chitosan microparticles for dust mite allergen. Trop J Pharm Res 10: 317-324, 2011.

TURELL MJ, BUNNING M, LUDWIG GV, ORTMAN B, CHANG J, SPEAKER T, SPIELMAN A, MCLEAN R, KOMAR N, GATES R, MCNAMARA T, CREEKMORE T, FARLEY L, MITCHELL CJ: DNA vaccine for West Nile virus infection in fish crows (Corvus ossifragus). Emerging Infect Dis 9: 1077-1081, 2003.

VUNAIN E, MISHRA AK, MAMBA BB: Dendrimers, mesoporous silicas and chitosan-based nanosorbents for the removal of heavy-metal ions: A review. Int J Biol Macromol 86: 570-586, 2016.

WANG T, ZOU M, JIANG H, JI Z, GAO P, CHENG G: Synthesis of a novel kind of carbon nanoparticle with large mesopores and macropores and its application as an oral vaccine adjuvant. Eur J Pharm Sci 44: 653-659, 2011.

WOOD R, MAO H, KEET C, MARTIN R: Pharmaceutical composition for treating allergic response in subject comprises primary film forming agent having water soluble polymers; biodegradeable plasticizer, excipients and carriers; mucoadhesive polymers; and allergen extract. Patent 2015125495A1, May 2015.

WURZ GT, KAO C-J, DEGREGORIO MW: Novel cancer antigens for personalized immunotherapies: latest evidence and clinical potential. Ther Adv Med Oncol 8: 4-31, 2016.

YEN H-H, SCHEERLINCK J-PY: Co-delivery of plasmid-encoded cytokines modulates the immune response to a DNA vaccine delivered by in vivo electroporation. Vaccine 25: 2575-2582, 2007.

ZEPP F: Principles of vaccine design-Lessons from nature. Vaccine 28: C14-C24, 2010.

ZHU L, LUO Y, JIANG Y, CHEN K, GAO M, CHEN Y, MAO Z, MAO J, GU C, WANG J, GAO L, PAN H, WANG Y, ZHUANG F, ZHOU K: Vaccine adjuvant useful as vaccine stabilizer, comprises trehalose, buffering agent for buffering pH, magnesium chloride, magnesium sulfate and amino acid. Patent 103110943A, May 2013. 